\title{
EXPERIMENTAL EVALUATION OF THE AERODYNAMIC PERFORMANCE OF SMALL WIND TURBINES CONFECTIONED IN 3D PROTOTYPING
}

\author{
S. O. Garré, \\ A. V. Paula, \\ J. L. R. Luz, \\ T. D. J. Vecina, \\ and A. P. Petry \\ Universidade Federal do Rio Grande do Sul \\ Escola de Engenharia \\ Departamento de Engenharia Mecânica \\ Programa de Pós-Graduação em Engenharia \\ Mecânica - PROMEC \\ Rua Sarmento Leite, 425 - $2^{\circ}$ Andar \\ CEP: 90.050-170, Bairro Centro \\ Porto Alegre, RS, Brasi \\ saulo.garre@ufrgs.br \\ Received: April 02, 2016 \\ Revised: May 10, 2016 \\ Accepted: June 11, 2016
}

ABSTRACT

This paper presents the experimental evaluation of the aerodynamic performance of two small wind turbines models with five blades in the Aerodynamic Tunnel Professor Debi Pada Sadhu. The models were confectioned on a reduced scale using 3D prototyping, the first one was designed using the blade element method, assuming the power coefficient of Betz, named Optimal Blade Betz (OBB) and the second is modified from the first one, named Optimal Blade Betz Modified (OBBM). The velocity distribution in the cross section of the tunnel was determined with the aid of a Pitot tube before the evaluation of the equipment. With the known tunnel velocity profile, the static torque of the prototypes were determined with the use of a digital torquemeter coupled to the machine axis, which recorded the readings for the speed range of $1 \mathrm{~m} / \mathrm{s}$ to $9.88 \mathrm{~m} / \mathrm{s}$. Also with the torquemeter, were evaluated the influence of the angular position of the blades in the measured torque. The blades were designed allowing vary their angular position in the hub, thus changing the angle of attack, and by consequence, the torque produced. A photo tachometer was employed to measure the rotation of the model in free spin. With the experimental data, the curves of static torque and angular velocity were determined as a function of incident speed. Through experimental determination of the incident velocity profile and the velocity profile in the aerodynamic wake of each turbine, the variation of the amount of momentum of the outflow was evaluated, and so the power extracted by the rotor in free rotation. This study aims to contribute to the design of a real small wind turbine, informing the aerodynamic characteristics of the equipment that can be constructed with this layout. The experimental results demonstrate good approximation for torque and power to the results obtained by evaluation by element of the blade method. The turbine constructed with Optimal Betz Blades presented static torque $17.8 \%$ higher than constructed with the Modified Blades and extracted 22\% more power from the air outflow.

Keywords: small wind turbine, wind energy, aerodynamic tunnel, experimental analysis

\section{NOMENCLATURE}

A area swept by the blades of the turbine, $\mathrm{m}^{2}$

$\mathrm{A}_{1}$ area that has aerodynamic wake before the turbine, $\mathrm{m}^{2}$

$\mathrm{A}_{3}$ area that has aerodynamic wake after the turbine, $\mathrm{m}^{2}$

$\mathrm{C}_{(\mathrm{p})} \quad$ power coefficient

$\mathrm{C}_{(\mathrm{r})} \quad$ chord the airfoil, $\mathrm{m}$

$\mathrm{C}_{\mathrm{D}} \quad$ coefficient of Drag

$\mathrm{C}_{\mathrm{L}} \quad$ coefficient of Lift

$\mathrm{C}_{\mathrm{P} \text { Real }}$ real power coefficient

$\mathrm{C}_{\mathrm{P} \text { Betz }}$ power coefficient of Betz

$\mathrm{D}$ diameter turbine, $\mathrm{m}$

$\mathrm{n}$ number of blades

$\mathrm{P}_{\mathrm{d}} \quad$ power available in the wind, $\mathrm{W}$

$\mathrm{P}_{\mathrm{e}} \quad$ power extracted from the wind, $\mathrm{W}$

$\mathrm{P}_{\text {barom }}$ barometric pressure, $\mathrm{mmHg}$

$\mathrm{P}_{\mathrm{din}}$ dynamic pressure, $\mathrm{Pa}$

$\mathrm{R}$ radius turbine, $\mathrm{m}$

$\mathrm{r}$ local radius, $\mathrm{m}$
$\mathrm{T} \quad$ temperature, $\mathrm{K}$

$\mathrm{U}_{\infty} \quad$ rated speed, $\mathrm{m} / \mathrm{s}$

$\mathrm{V}_{\mathrm{MI}}$ velocity measured at the inclined manometer, $\mathrm{m} / \mathrm{s}$

w wind speed relative to the aerodynamic profile, $\mathrm{m} / \mathrm{s}$

3D three dimensions: $\mathrm{x} ; \mathrm{y} ; \mathrm{z}$

\section{Greek symbols}

$\alpha_{\mathrm{A}} \quad$ angle of attack

$\beta_{(\mathrm{r})} \quad$ twist angle of the blade

$\gamma$ angle between the relative wind and the wind incident

$\eta \quad$ system efficiency

$\lambda_{\mathrm{D}} \quad$ blade tip ratio

$\mu \quad$ air dynamic viscosity, $\mathrm{kgfs} / \mathrm{m}^{2}$

$v \quad$ kinematic viscosity of air, $\mathrm{m}^{2} / \mathrm{s}$

$\rho \quad$ air density, $\mathrm{Kg} / \mathrm{m}^{3}$

$\rho_{\text {Air dia }}$ air density set to the date and time of measurement, $\mathrm{kg} / \mathrm{m}^{3}$ 
$\Omega$

angular velocity, $\mathrm{rad} / \mathrm{s}$

\section{INTRODUCTION}

Wind energy is already a reality in our country, spread primarily through wind farms with large wind turbines. However there is a government effort to decentralize this generation. Small wind turbines can bring a new reality to the Brazilian energy generation promoting this decentralization becoming also an outlet for water and contributing to the electric energy matrix diversification.

Analytical and numerical methods are used for the design of wind turbines. The power and torque curves of the may predicted by the design method, but must be evaluated experimentally to verify theoretical analysis.

As the most informative data equipment is its power curve, an objective of this work is to experimentally determine the power curve through the torque curve of two prototype built on a reduced scale.

Another objective of this work is to contribute to the research project "Design and construction of a Small Wind generator with inherent safety," informing the aerodynamic characteristics that the actual turbine, as designed, will present.

Finally we intend to predict coefficients correlating the data with numerical simulation with the data collected in the laboratory and finally with those observed when the actual turbine up and running. These factors will enable the prediction of reliable power curves from previous data, without making the construction of a real turbine for tests.

To do so is made a general review of IEC 61400-2, ABNT NBR IEC 61400-12-1 and IEC 61400-11 also observing the provisions of Normative Resolution No. 482 establishing the general rules for the Microgeneration access and minigeneration Distributed and Clearing System of Electricity and Decree $N^{\circ} 85$ stipulating the Conformity Assessment Requirements for Wind Turbines - RAC.

\section{EXPERIMENTAL METODOLOGY}

\section{Design and Prototype Construction Process}

The first model was designed using the blade element method, assuming the power coefficient of Betz, named Optimal Blade Betz (OBB) and the second is modified from the first one, named Optimal Blade Betz Modified (OBBM).

$$
C_{(r)}=\frac{1}{n} 2 \pi R \frac{8}{9 C_{L}} \frac{1}{\lambda_{D} \sqrt{\lambda_{D}^{2}\left(\frac{r}{R}\right)^{2}+\frac{4}{9}}}
$$

$$
\beta_{(r)}=\arctan \left(\frac{3 r}{2 R} \lambda_{D}\right)+\alpha_{A}
$$

For design of the blades of the first one the equations adopted for the calculation of the chord $(C(r))$ and the blade twist angle $(\beta(r))$ were Eq. (1) and Eq. (2) respectively (Burton, 2001; Gasch and Twele, 2002).

Table 1 presents principal data used to define the model of the wind turbine.

\begin{tabular}{|c|c|c|}
\hline Radius $(R)$ & Diameter $(D)$ & Area $(A)$ \\
\hline $0.25 \mathrm{~m}$ & $0.5 \mathrm{~m}$ & $0.196 \mathrm{~m}$ \\
\hline (m) & $(\mathrm{m})$ & (m) \\
\hline$\pi$ & $\begin{array}{c}\text { Mass Specific } \\
\text { Air }(\rho)\end{array}$ & $\begin{array}{c}\text { Blades Number } \\
\quad(n)\end{array}$ \\
\hline 3.14159265 & 1.225 & 5 \\
\hline adimensional & $\mathrm{Kg} / \mathrm{m}^{3}$ & adimensional \\
\hline $\begin{array}{c}\text { Torque } \\
\text { Maximum }\end{array}$ & $\begin{array}{l}\text { Power Available } \\
\text { Wind }\left(P_{d}\right)\end{array}$ & $C_{P \text { Real }}$ \\
\hline 0.593 & 120.26 & 0.444 \\
\hline N.m & W & adimensional \\
\hline $\begin{array}{c}\text { Extracted } \\
\text { Wind Power } \\
\left(P_{e}\right)\end{array}$ & Real Torque & $\begin{array}{l}\text { Rated Speed } \\
\qquad\left(U_{\infty}\right)\end{array}$ \\
\hline 53.52 & 0.45 & 10 \\
\hline $\mathrm{W}$ & N.m & $\mathrm{m} / \mathrm{s}$ \\
\hline $\begin{array}{c}\text { Speed Ratio } \\
\text { Blade Tip }\left(\lambda_{D}\right)\end{array}$ & Parties Divided & $\begin{array}{c}\text { Angular } \\
\text { Velocity }(\Omega)\end{array}$ \\
\hline 3 & 25 & 120 \\
\hline adimensional & arbitrated & $\mathrm{rad} / \mathrm{s}$ \\
\hline dr & $\mathbf{C}_{\text {P Betz }}$ & Power Maxim \\
\hline 0.01 & 0.593 & 71.27 \\
\hline $\mathrm{m}$ & adimensional & W \\
\hline $\begin{array}{c}\text { Drag } \\
\text { Coefficient } \\
\left(C_{D}\right)\end{array}$ & $\begin{array}{l}\text { Lift Coefficient } \\
\qquad\left(C_{L}\right)\end{array}$ & $\varepsilon\left(C_{L} / C_{D}\right)$ \\
\hline 0.018 & 1.15 & 63.89 \\
\hline adimensional & adimensional & adimensional \\
\hline $\begin{array}{c}\text { Angle of } \\
\text { Attack }\left(\alpha_{A}\right)\end{array}$ & $\mathbf{r}$ & Speed Profile \\
\hline 10 & $0.01-0.25$ & NACA 0012 \\
\hline${ }^{\circ}$ & $\mathrm{m}$ & - \\
\hline
\end{tabular}

Table 1. Input data.

Table 1 shows the data that was entered in the equations to enable the acquisition of the project values, which allowed the construction of prototype blades.

The parameters are defined according to the following:

Blades Number - Chosen as review by Verdum (2013);

Speed Ratio Blade Tip - Defined through the analysis 
by Gasch and Twele (2002), which correlates the $\lambda_{D}$ value for equipment with varying number of blades;

$$
\begin{gathered}
P_{\text {Max }}=C_{P B e t z}\left(\frac{1}{2} \rho A U_{\infty}^{3}\right) \\
T_{w \operatorname{Max}}=\frac{1}{2} \rho \pi R^{3} U_{\infty}^{2}\left(\frac{C_{P B e t z}}{\lambda_{D}}\right)
\end{gathered}
$$

Power Maximum ( $\left.P_{\text {Max }}\right)$ Eq. (3) and Torque Maximum $\left(T_{w \text { Max }}\right)$ Eq. (4) - To determine its value is used the ideal power coefficient, ie $C_{P \text { Betz }}$;

$$
P_{d}=\left(\frac{1}{2} \rho A U_{\infty}^{3}\right)
$$

Power Available Wind (Eq. (5)) - all the power that the air outflow can provide without considering the influence of the turbines;

Extracted Wind Power - Make a comparative analysis between the catalog data of some equipment that have been tested and simulated. With this analysis it is observed that generally the $C_{P}$ Real is on average $25 \%$ less than the $C_{P}$ Betz. Which results at a lower power in the same proportion. This preliminary analysis is necessary for the Real Torque prediction of the turbine, so that it determines the nominal capacity that a digital torquimeter needs to possess for, after testing, to inform the read values of the static torque provided by the prototype, when exposed to speed up to $10 \mathrm{~m} / \mathrm{s}$ in the aerodynamic tunnel;

Drag Coefficient and Lift Coefficient - For the determination of the values of $C_{D}$ and $C_{L}$ is used graphical analysis available in Airfoil Tools website, which is a database that has a wide range of information from different airfoils.

With this analysis we define the aerodynamic profile of the blades of the prototypes, in this particular case, you choose by NACA 0012.

At the images of Fig. 1 the prototype and some construction details are presented. To measure the torque a torquimeter would be used for data acquisition, made the calculation of the forces acting on the blades in order to meet up the power and finally the torque. The torque value calculated for the 10th attack angle was $0.265 \mathrm{Nm}$. Recalling that in this particular case the torque was calculated static, ie those used Equations not considered the angular velocity or local radius.

For the $3 \mathrm{D}$ printing process it was dedicated 80 hours to printer tests and the resulting pieces and 120 hours for prototyping turbine. An advanced study of 3D printing and also meet up the properties of the filaments used as raw material was required, as well as the most suitable printer settings so that it had the best pieces in the shortest time possible. Before starting printing parts (Fig. 1a) noted the need to divide up the shovel in 3 equal portions every $75 \mathrm{~mm}$, $\mathrm{z}$ since the printer was a maximum dimension of 100 $\mathrm{mm}$, and each blade was $225 \mathrm{~mm}$ long. Thus, each prototype needed 17 parts PLA (Polylactic acid derived from corn or sugarcane) to be built. In a second shaft and bearings ABEC 7, the results can be seen in Fig. 1b and Fig. 1c.
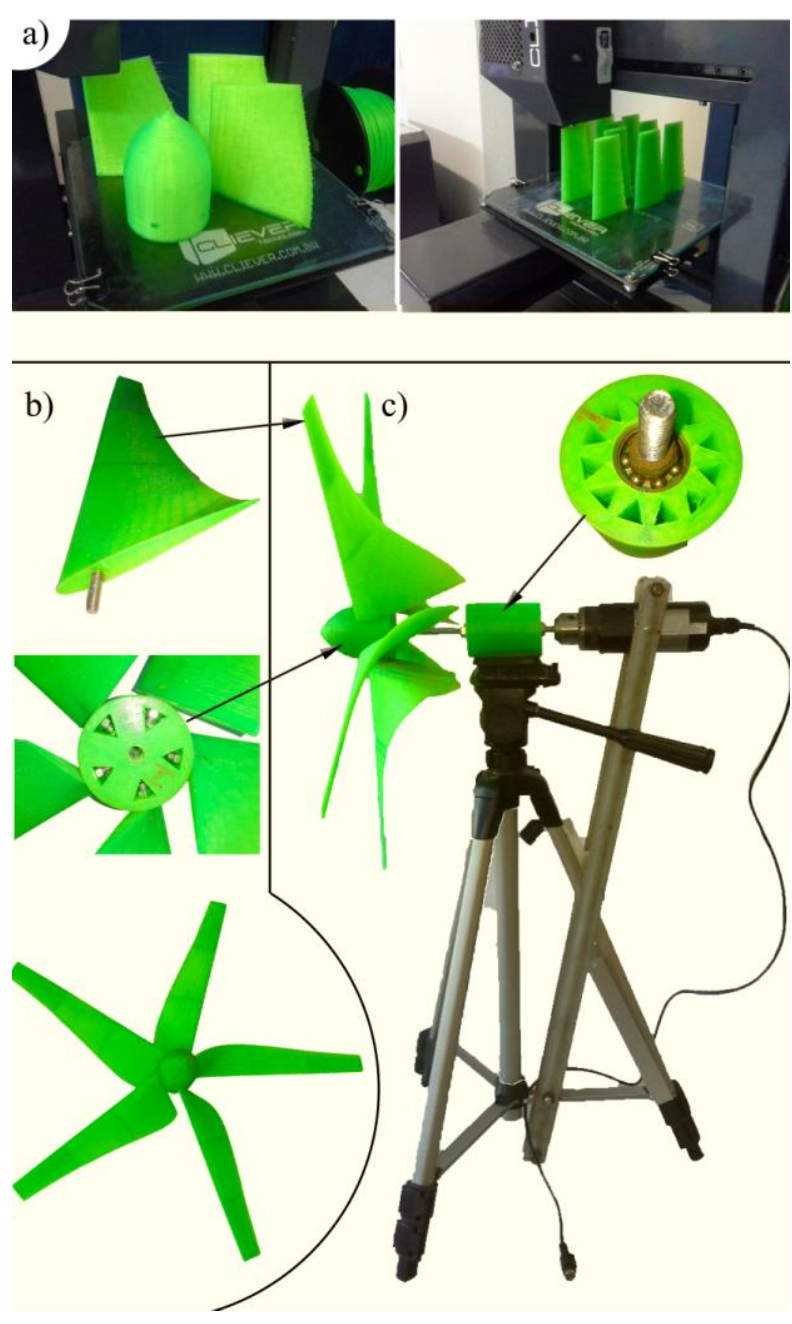

Figure 1. a) Printing of parts; b) Details of the socket of the blades; c) Installation and detailing the prototype shaft.

\section{Experimental Determination of the Aerodynamic Tunnel Velocity Profile}

The Aerodynamic Tunnel Professor Debi Pada Sadhu is a suction tunnel with square section channel of $1 \mathrm{~m}^{2}$ $(1 \mathrm{~m} \times 1 \mathrm{~m})$, the velocity profile is defined for the frequencies of a inverter from $20 \mathrm{~Hz}$ to $50 \mathrm{~Hz}$. The velocity distribution on the experimental section of the tunnel was determined using two Pitot tubes one connected to an inclined manometer (MI) and other electronic (ME). The Pitot connected to the MI was the reference one and its position was kept constant, the position of the ME Pitot varies vertical and 
horizontally, forming a mesh of measuring points. Fig. 2 shows graphically the speed for the rage of frequency of the inverter.
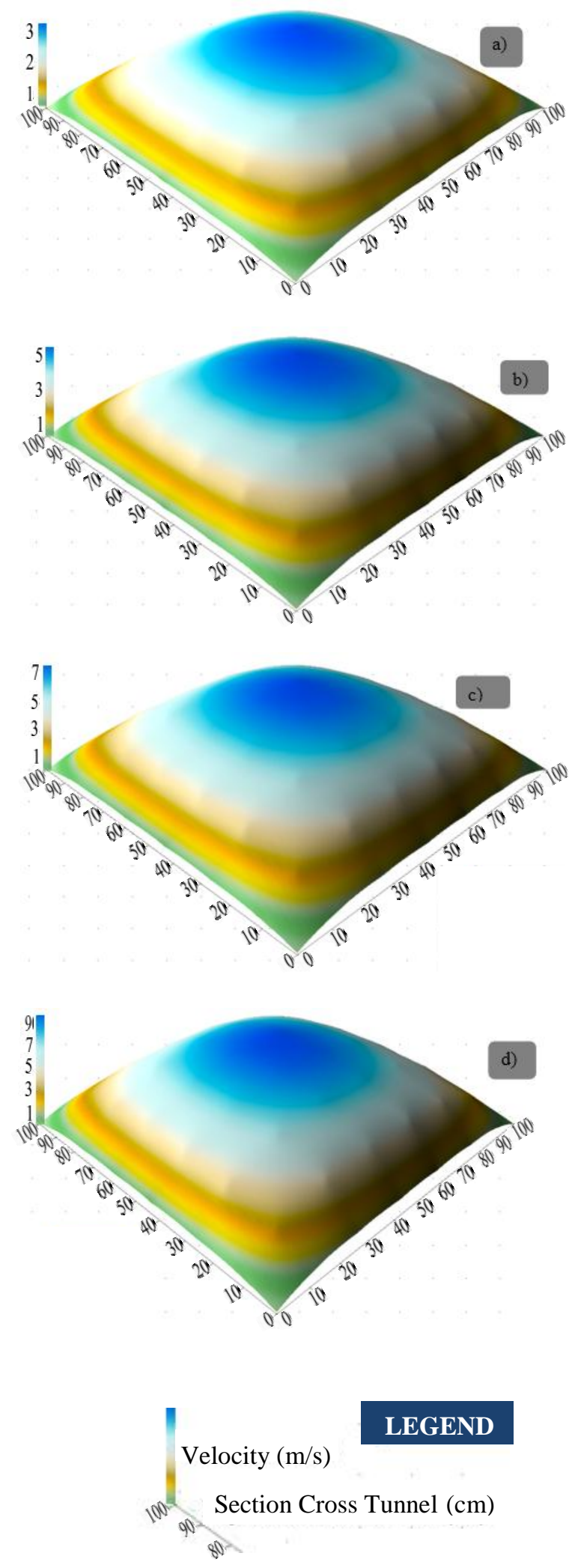

Figure 2. Velocity profile of tunnel aerodynamic: a) $20 \mathrm{~Hz}$; b) $30 \mathrm{~Hz}$; c) $40 \mathrm{~Hz}$; d) $50 \mathrm{~Hz}$.
The results presented in Fig.2 show small speed variation and the profile was almost constant near the channel walls and somewhat blunt the closer the center tunnel. Knowing the velocity profile is the prototype mounted inside the tunnel and measured torque, revolutions per minute and it was determined experimentally the wake of the turbine based on the theory of Betz, the graphical representation is presented in Fig. 3

\section{Experimental Determination of Aerodynamic wake Using a Similar Model in the Proposal for Betz}

To determine the aerodynamic wake, presented in Fig. 3 it were used two Pitot tubes positioned before and after the turbine. With this set up the input speed and output speed were measured. Comparing the profiles it is possible to estimate the variation of momentum and calculate the power extracted from the flow and finally the power coefficient $\left(C_{P \text { Potot }}\right)$ for the two prototypes. For the inverter set to $30 \mathrm{~Hz}$ for the OBB turbine the $C_{P}$ obtained was of $37.6 \%$, for the turbine OBBM the obtained value was of $28.6 \%$.
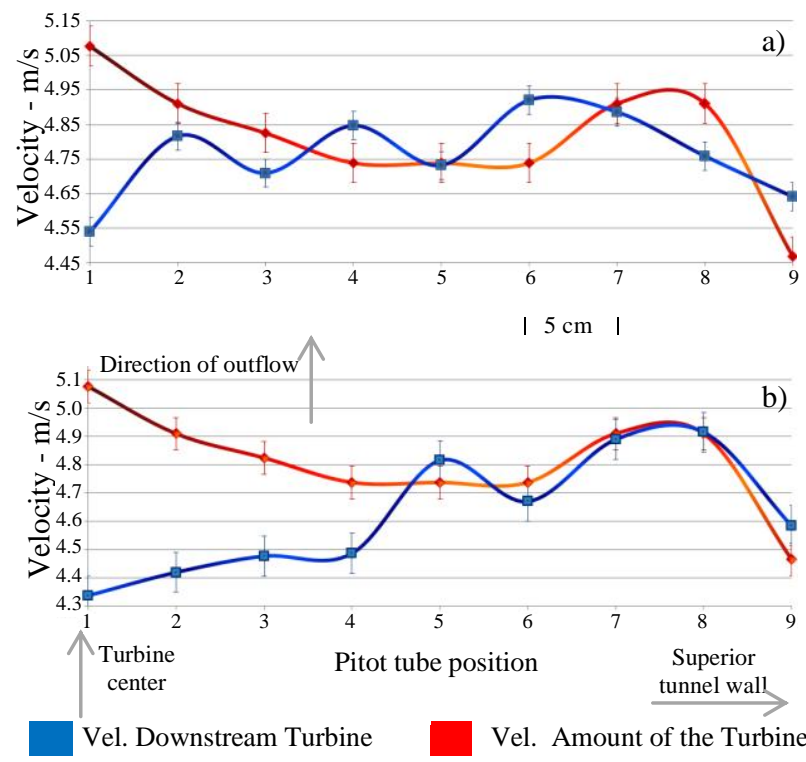

Figure 3. Aerodynamic wake for: a) Modified Optimal Betz Turbine; b) Turbine Betz Optimal Frequency: $30 \mathrm{~Hz}$.

Fig. 3 shows vertical lines on each measured point are error bars calls and representatives of the uncertainty values calculated for each case.

\section{Determining the Static Torque Curve, RPM Curve and the Numerical Power Curve}

The Static torque curve (Fig. 4) and the angular velocity curve (Fig. 5) was determined experimentally. 


$$
P_{\text {protot }}=C_{\text {Pprotot }}\left(\frac{1}{2} \rho A_{\text {coef }}^{3}\right)
$$

While the power curve shown in Fig. 6 was determined by calculation (Eq. (6)), that is, a forecast of what it is expected to when the turbine is loaded.

It is presented in Eq. (6): $P_{\text {protot }}$ is the estimated power for each prototype. $C_{\text {Pprotot }}$ is the power coefficient of the prototype. $v_{\text {coef }}$ is the speed taking into account a decrease coefficient (14.3\% to OTBM and $12.5 \%$ to OTB) derived from the relationship between the flow velocity with clear tunnel of the channel and the flow velocity measured when the channel is blocked by the turbine. $A$ area turbine is comprised of $0.196 \mathrm{~m}^{2}$ and $\rho$ is the air density.

For the determination of the static torque tunnel speed was increased and the fixed shaft torque wrench reading the prototype was made. Already, the angular velocity was determined by a digital tachometer photo appointed to the prototype in free spin. The torque and the angular velocity was measured for the two types of blades by varying its position $(P 1, P 2$ and $P 3)$. Since $P 1$ is the rope twist angle 1 calculated in the project, this is, $20.20^{\circ}$. $P 2$ angle was determined using the value $P 1$ added $15^{\circ}$ and used to $P 3-P 2$ is added $15^{\circ}$. Thus, for presentation purposes, the angles are named $20^{\circ}, 35^{\circ}$ and $50^{\circ}$. With the data obtained the static torque curve for the two types of blades is provided for the blades positioned at three different angles.

\section{RESULTS AND DISCUSSION}

\section{Standardization and 3D Prototyping}

The revised of regulation developed for this work, which describes the methodology necessary for the Small Wind Turbine Certification in Brazil and in the world, still does not prescribe a clear methodology for the development of small wind turbines tests in aerodynamic tunnel. However, Annex $H$ of IEC 61400-12-1 presents the recommendations to conduct the field tests. Some characteristics of this Annex may be adapted and used for tests in the laboratory.

3D prototyping administered in this study shows the ability to generate profiles and blades with high fidelity, which allows the quality of presented data. The cost of the printing process, done on site, was optimized compared with outsourcing service.

The blade element theory was used to design the blades of a wind turbine prototype. By the envisaged equations can be a final product able to simulate the actions of a real equipment. The OTBM (Optimal Turbine Betz Modified) received 12\% less material compared to the OTB (Optimal Turbine Betz) resulting in a lighter turbine, but more fragile.
Fig. 3 shows a comparison between aerodynamic wake OTBM (Fig. 3a) and OTB (Fig. 3b) and confirms the difference arising from the design of developed blades, since OBBM (Optimal Blades Betz Modified) have an area smaller than the OBB (Optimal Blades Betz) and therefore results in less retention rate of air flow. In Positions 1 and 9 both OTBM as the OTB have similar behavior retaining more flow in the center (Position 1) and declining to approach the upper wall of the tunnel (Position 9). In the other speed positions observed for the amount when the tunnel is blocked by OTBM, undergoes a small decrease as compared when the same analysis is done for the OTB, while the downstream speed undergoes variation depending on the type of turbine. In Positions 1 to 4 is possible to note that the larger the OBB rope lengths enable a better retention of the air flow. In Position 6 runoff still suffers variations caused by aerodynamic wake. This effect reduces as the air flow moves away from the tips of the turbine blades and approaches the upper wall of the aerodynamic tunnel.

For the determination of the uncertainties are used partial derivatives known as sensitivity coefficients of Kline \& McClintock (1953).

When the partial derivatives be solved by means of engineering software that allows the entry of the measurements obtained by the errors of each measurement (Tab. 2 and Tab. 3).

Table 2. Uncertainties in measurements for the aerodynamic wake of the OTBM with the tunnel motor inverter operating frequency of $30 \mathrm{~Hz}$.

\begin{tabular}{c|c|c}
\hline $\begin{array}{c}\text { Measured } \\
\text { Data }\end{array}$ & $\begin{array}{c}\text { Absolute } \\
\text { Uncertainty } \\
\mathbf{\pm}\end{array}$ & $\begin{array}{c}\text { Relative } \\
\text { Uncertainty } \\
(\boldsymbol{\%})\end{array}$ \\
\hline$P_{\text {barom }}$ & 66.66 & 0.1 \\
\hline$P_{\text {din }}$ & 1.8 & 13.5 \\
\hline$\rho$ & 0.0008764 & 0.1 \\
\hline$T$ & 0.297 & 0.1 \\
\hline$V_{M E}$ & 0.3221 & 6.8 \\
\hline$V_{M I}$ & 0.03452 & 0.7 \\
\hline
\end{tabular}

Table 3. Uncertainties in measurements for the aerodynamic wake of the OTB with the tunnel motor inverter operating frequency of $30 \mathrm{~Hz}$.

\begin{tabular}{c|c|c}
\hline $\begin{array}{c}\text { Measured } \\
\text { Data }\end{array}$ & $\begin{array}{c}\text { Absolute } \\
\text { Uncertainty } \\
\mathbf{\pm}\end{array}$ & $\begin{array}{c}\text { Relative } \\
\text { Uncertainty } \\
(\boldsymbol{\%})\end{array}$ \\
\hline$P_{\text {barom }}$ & 66.66 & 0.1 \\
\hline$P_{\text {din }}$ & 1.778 & 15.0 \\
\hline$\rho$ & 0.0008736 & 0.1 \\
\hline$T$ & 0.298 & 0.1 \\
\hline$V_{M E}$ & 0.3342 & 7.4 \\
\hline$V_{M I}$ & 0.03451 & 0.7 \\
\hline
\end{tabular}

Torque Static Mechanical

\section{Aerodynamic Wake}


The Mechanical Static Torque, estimated by Burton, T. (2001) adapted equations, is $9.1 \%$ higher than the experimentally determined (Fig. 4).

Fig. 4 shows the measured torque varying the position of the blades for the OBB and for OBBM.

When changing the positions $(P 1, P 2$ and $P 3)$ the torque measured with blades at $35.20^{\circ}$ have the greater values for both models. The lowest value was measured in the project position $\left(20.20^{\circ}\right)$ growing toward $P 2$ and reducing in $P 3\left(50.20^{\circ}\right)$, new tests should be done to determine the optimal position of the blades to the start of the turbine. Since, on a preliminary estimate, it is possible to say that this position will be around $35.20^{\circ}(P 2)$.
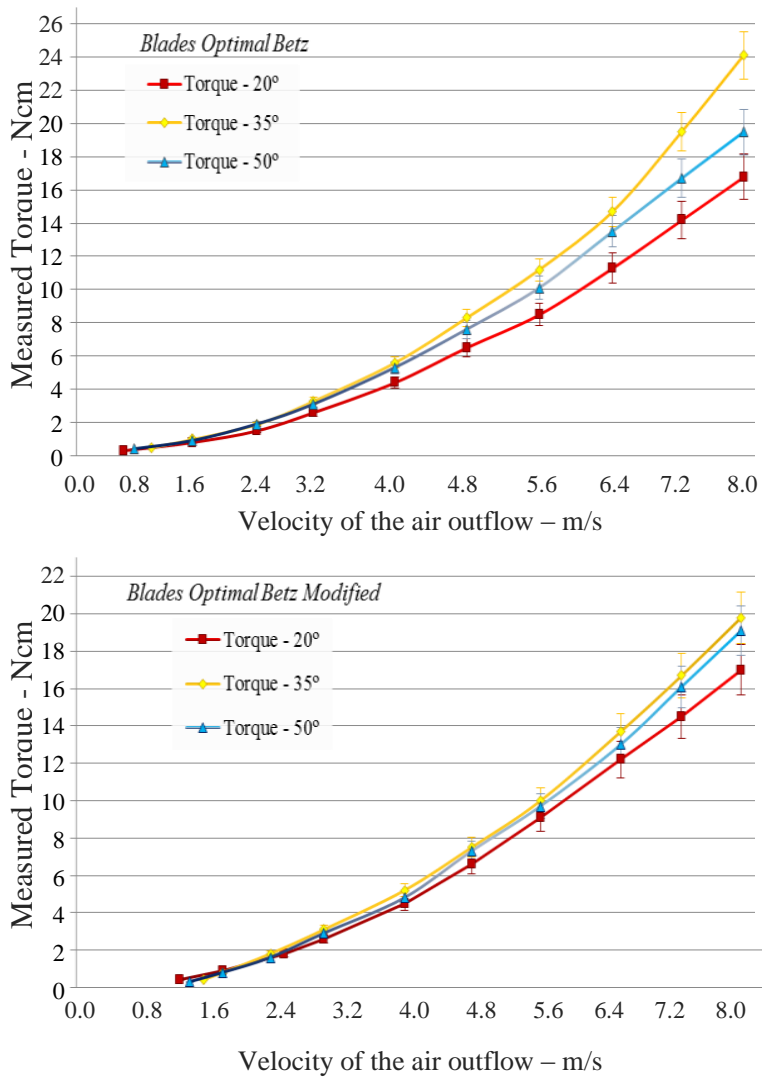

Figure 4. Torque curve.

Similarly to that observed for the aerodynamic wake partial derivatives are resolved and uncertainties for static torque readings are listed (Tab. 4 - Tab. 9).

Also in the respective tables already presented uncertainties for angular velocity obtained data.

Table 4. Uncertainties in the measurements for the static mechanical torque and RPM generated when the OBB are in $P 1-20.20^{\circ}$.

\begin{tabular}{c|c|c}
\hline $\begin{array}{c}\text { Measured } \\
\text { Data }\end{array}$ & $\begin{array}{c}\text { Absolute } \\
\text { Uncertainty } \\
\mathbf{\pm}\end{array}$ & $\begin{array}{c}\text { Relative } \\
\text { Uncertainty } \\
(\%)\end{array}$ \\
\hline$P_{\text {barom }}$ & 66.66 & 0.1 \\
\hline$\rho$ & 0.0008736 & 0.1 \\
\hline$T W E$ & 0.13175 & 2.4 \\
\hline
\end{tabular}

\begin{tabular}{|c|c|c|}
\hline$R P M$ & 1.4135 & 0.1 \\
\hline$V_{M I}$ & 0.04021 & 0.9 \\
\hline
\end{tabular}

Table 5. Uncertainties in the measurements for the static mechanical torque and RPM generated when the OBB are in $P 2-35.20^{\circ}$.

\begin{tabular}{c|c|c}
\hline $\begin{array}{c}\text { Measured } \\
\text { Data }\end{array}$ & $\begin{array}{c}\text { Absolute } \\
\text { Uncertainty } \\
\mathbf{\pm}\end{array}$ & $\begin{array}{c}\text { Relative } \\
\text { Uncertainty } \\
(\%)\end{array}$ \\
\hline$P_{\text {barom }}$ & 66.66 & 0.1 \\
\hline$\rho$ & 0.0008736 & 0.1 \\
\hline$T W E$ & 0.15425 & 2.2 \\
\hline$R P M$ & 0.85075 & 0.1 \\
\hline$V_{M I}$ & 0.04021 & 0.9 \\
\hline
\end{tabular}

Table 6. Uncertainties in the measurements for the static mechanical torque and RPM generated when the $\mathrm{OBB}$ are in $P 3-50.20^{\circ}$.

\begin{tabular}{c|c|c}
\hline $\begin{array}{c}\text { Measured } \\
\text { Data }\end{array}$ & $\begin{array}{c}\text { Absolute } \\
\text { Uncertainty } \\
\mathbf{\pm}\end{array}$ & $\begin{array}{c}\text { Relative } \\
\text { Uncertainty } \\
(\boldsymbol{\%})\end{array}$ \\
\hline$P_{\text {barom }}$ & 66.66 & 0.1 \\
\hline$\rho$ & 0.0008736 & 0.1 \\
\hline$T W E$ & 0.14675 & 2.3 \\
\hline$R P M$ & 0.54175 & 0.1 \\
\hline$V_{M I}$ & 0.04021 & 0.9 \\
\hline
\end{tabular}

Table 7. Uncertainties in the measurements for the static mechanical torque and RPM generated when the OBBM are in $P 1-20.20^{\circ}$.

\begin{tabular}{c|c|c}
\hline $\begin{array}{c}\text { Measured } \\
\text { Data }\end{array}$ & $\begin{array}{c}\text { Absolute } \\
\text { Uncertainty } \\
\pm\end{array}$ & $\begin{array}{c}\text { Relative } \\
\text { Uncertainty } \\
(\%)\end{array}$ \\
\hline$P_{\text {barom }}$ & 66.66 & 0.1 \\
\hline$\rho$ & 0.0008736 & 0.1 \\
\hline$T W E$ & 0.13325 & 2.4 \\
\hline$R P M$ & 1.3525 & 0.1 \\
\hline$V_{M I}$ & 0.03727 & 0.8 \\
\hline
\end{tabular}

Table 8. Uncertainties in the measurements for the static mechanical torque and RPM generated when the OBBM are in $P 2-35.20^{\circ}$.

\begin{tabular}{c|c|c}
\hline $\begin{array}{c}\text { Measured } \\
\text { Data }\end{array}$ & $\begin{array}{c}\text { Absolute } \\
\text { Uncertainty } \\
\mathbf{\pm}\end{array}$ & $\begin{array}{c}\text { Relative } \\
\text { Uncertainty } \\
(\boldsymbol{\%})\end{array}$ \\
\hline$P_{\text {barom }}$ & 66.66 & 0.1 \\
\hline$\rho$ & 0.0008736 & 0.1 \\
\hline$T W E$ & 0.14525 & 2.3 \\
\hline$R P M$ & 0.88925 & 0.1 \\
\hline$V_{M I}$ & 0.03727 & 0.8 \\
\hline
\end{tabular}

Table 9. Uncertainties in the measurements for the static mechanical torque and RPM generated when the OBBM are in $P 3-50.20^{\circ}$.

\begin{tabular}{|c|c|c|}
\hline $\begin{array}{c}\text { Measured } \\
\text { Data }\end{array}$ & $\begin{array}{c}\text { Absolute } \\
\text { Uncertainty } \\
\mathbf{\pm}\end{array}$ & $\begin{array}{c}\text { Relative } \\
\text { Uncertainty } \\
(\boldsymbol{\%})\end{array}$ \\
\hline$P_{\text {barom }}$ & 66.66 & 0.1 \\
\hline$\rho$ & 0.0008736 & 0.1 \\
\hline
\end{tabular}




\begin{tabular}{|c|c|c|}
\hline$T W E$ & 0.14075 & 2.3 \\
\hline$R P M$ & 0.55875 & 0.1 \\
\hline$V_{M I}$ & 0.03727 & 0.8 \\
\hline
\end{tabular}

\section{Angular Velocity}

The angular velocity measured for the turbines in free spin for different velocities of the air flow is presented in Fig. 5. The graphs are expressed in rotations per minute observed in relation to the speed of the air flow in the interior of the aerodynamic tunnel. This analysis is important for estimating the angular velocity $(\Omega)$. Through the measures of the angular velocity the power and the dynamic torque may be estimated through these relations and data can be relevant in order to provide power to the actual equipment.

In comparison, the highest readings of angular velocity are observed when the $\mathrm{OBB}$ is with the blades in Position 1 (design position) to $20.20^{\circ}$. As best results observed for the static torque is when the $\mathrm{OBB}$ is with the blades in Position $2\left(35.20^{\circ}\right)$.

Analyzing the curves presented in Fig. 5 it is possible observe similar behavior for both turbines.
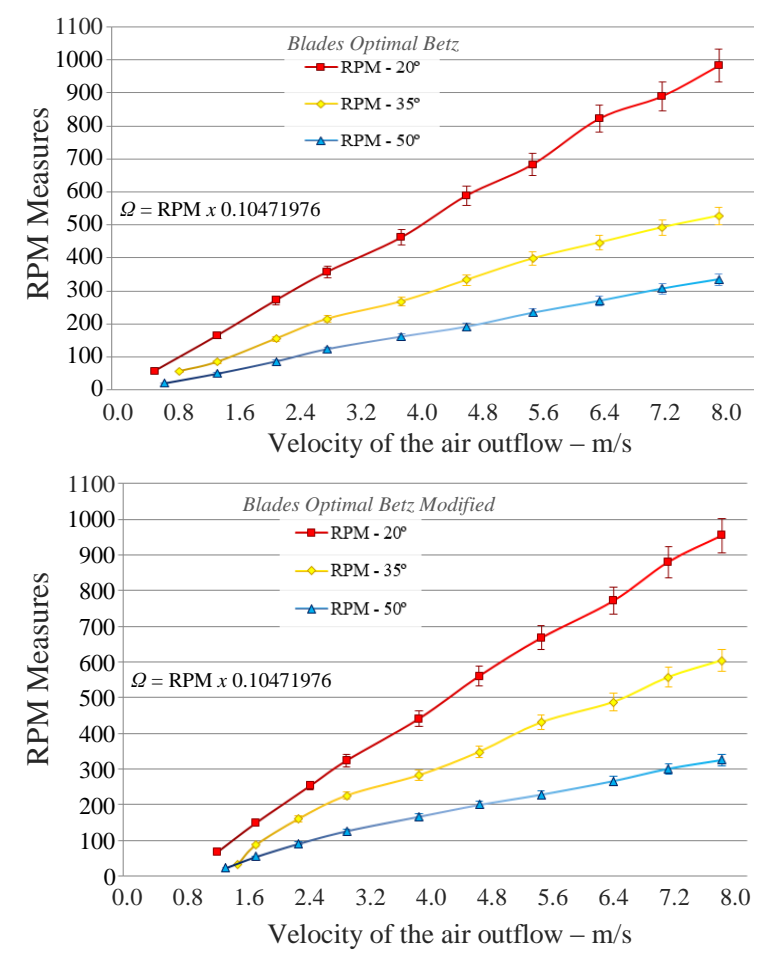

Figure 5. RPM curve.

Performance analysis, observing each turbine individually, we have the $\mathrm{OBB}$ with the blades positioned $20.20^{\circ}$ has the highest angular speed when compared with blades positioned at $35.20^{\circ}$ ( $\Omega$ is $46.3 \%$ lower) and at $50.20^{\circ}$ ( $\Omega$ is $69,5 \%$ lower). The same behavior is observed for OBBM, but with blades positioned at $35.20^{\circ}$ the angular velocity is $36.7 \%$ lower than and when the blades are positioned $50.20^{\circ}$ the angular velocity is $65.9 \%$ lower than when the blades positioned at $20.20^{\circ}$.

The starting speed analysis shows better performance on tests is the OBB $20.20^{\circ}$ giving the match with wind speed measured $0.58 \mathrm{~m} / \mathrm{s}$. However, both run at very low flow rates.

The turbine that demand higher wind speed to go is with OBBM in $P 2$, recording $1.58 \mathrm{~m} / \mathrm{s}$ as a starting speed.

\section{Power Curve}

The extracted power by OBB model is $22.2 \%$ higher than the extracted power of the airflow by OBBM, estimated from the momentum difference observed in the air flow upstream and downstream the turbine (Fig. 3), Therefore the OBB model requires more material, this type of blade should be preferred to the blade OBBM blade.

In Fig. 6 the power estimated versus velocity curve is presented, the power calculated does not take into account the electrical generator efficiency.
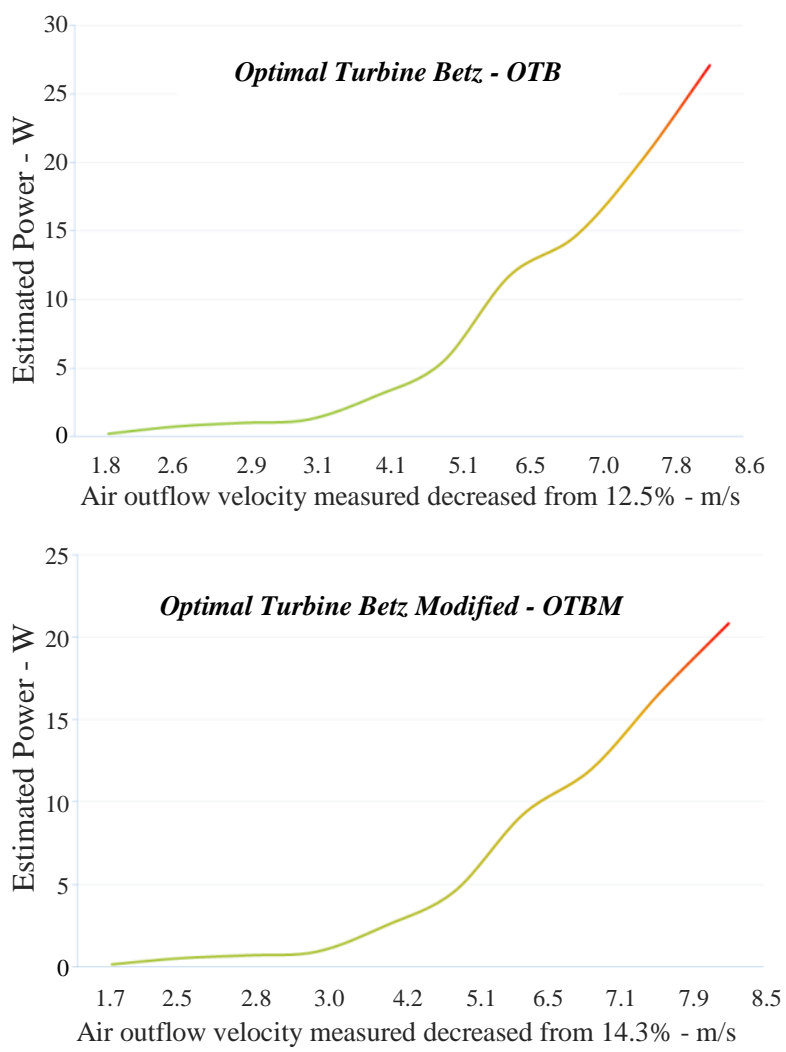

Figure 6. Calculated power curve.

As the aerodynamic tunnel does not reach speeds exceeding $9.88 \mathrm{~m} / \mathrm{s}$ while being partially obstructed by the turbine does not have a speed exceeding $8.6 \mathrm{~m} / \mathrm{s}$, the graphical representation shown in Fig. 6 shows the power curves such that equipment has to be tested at low speeds.

From the curves of Fig. 6 and considering that the actual turbine is designed to work with speeds up to $10 \mathrm{~m} / \mathrm{s}$, the estimated power curve is constructed 
for each prototype (Fig. 7).

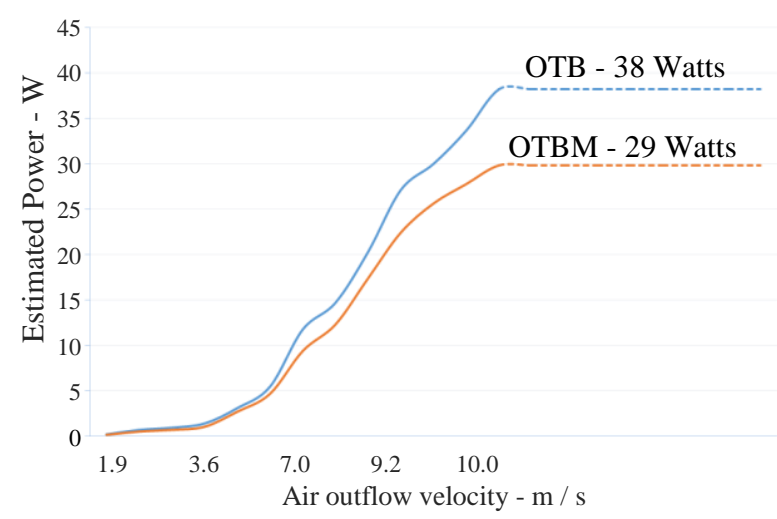

Figure 7. Estimated power curve.

To do so, it uses an extrapolation of observed rates in the aerodynamic tunnel, because the readings do not reach the $10 \mathrm{~m} / \mathrm{s}$ in either of the speed profiles described above.

The power curve of Fig. 7 has a power control suggestion by changing the tilt angle of the blades (dashed lines) as it makes this kind of testing in this study.

\section{CONCLUSIONS}

The small wind turbine market in Brazil is in gradual and ascending development. However, the data informed to consumers do not always go along with this development. The aerodynamic characteristics and performance of a wind machine must follow the described by the rules to provide greater accuracy and credibility in the reported data. This standardization of the tests has benefits that can impact the expansion and dissemination of this technology.

$3 \mathrm{D}$ prototyping administered in this work allows the development of profiles with a high degree of structural and aerodynamic loyalty which ensures the reliability of the measured data. Through experimental analysis of aerodynamic wake of a small-scale model tested in aerodynamic drag tunnel and made for 3D prototyping is estimated a power coefficient $\left(\mathrm{C}_{\mathrm{p} \text { protot }}\right)$ of $35 \%$ for the OBB and $28.6 \%$ for OBBM.

Analyzing the power curves of the models tested in $P 1-20.20^{\circ}$ the OBB extracts $22 \%$ more power flow than OBBM. The experimental results demonstrate torque and power good approximation to the results obtained for analytical evaluation.

It is noted that experimental results in the best static torque blade position is $P 2-35.20^{\circ}$, and in this position the turbine $\mathrm{OBB}$ static torque is $17.8 \%$ greater than the built with blades changed (OBBM).

The starting speed and angular velocity, which has better performance on tests is the OBB in $P 1$ $20.20^{\circ}$, giving the match with wind speed measured
$0.58 \mathrm{~m} / \mathrm{s}$. Registering maximum revolution to 8.6 $\mathrm{m} / \mathrm{s}$.

The experiments presented in this work, in addition to the efforts of other researchers and collaborators will contribute to the design of a real wind turbine, the data obtained experimentally should be compared with those observed when the actual turbine into operation. Thus, one can develop coefficients correlating the power curve experimentally raised in the laboratory with that is displayed when the machine is actually built. Thus, this correlation will bring more reliability when designing is a small wind turbine, because before the turbine building, it will be possible to predict with an acceptable degree of accuracy as the equipment will generate energy.

It is expected in the future be possible to describe a new methodology, based on correlation coefficients, determined a reliable power curve through simulation or prototyping before starting to build a full-scale equipment.

\section{ACKNOWLEDGEMENTS}

Authors gratefully acknowledge the support by the $\mathrm{CNPq}$ - National Council for Scientific and Technological Development, Ministry of Science and Technology (MCT), Brazil.

Saulo de Oliveira Garré thanks also the CAPES for granting him a fellowship.

\section{REFERENCES}

Audierne, E., Elizondo, J., Bergami L., Ibarra H., and Probst, O., 2010, Analysis of the Furling Behavior of Small Wind Turbines, Applied Energy, Vol. 87, pp. 2278-2292.

AWEA, 2010, AWEA Small Wind Global Market Study 2010, American Wind Energy Association.

Balat, M., A, 2009, Review of Modern Wind Turbine Technology, Energy Sources, Part A, Vol. 31, pp. 1561-1572.

BRASIL, 2012, Agência Nacional de Energia Elétrica - ANEEL. Resolução Normativa $n^{o} 482$, de 17 de abril de 2012, Diário Oficial da União, Brasília, DF, Seção 1, Vol. 149, No. 176, pp. 53. (in Portuguese)

Burton, T., Sharp, D., Jenkins, N., and Bossanyi, E., 2001, Wind Energy Handbook, John Wiley \& Sons.

Gasch, R., and Twele, J., 2002, Wind Power Plants. Fundamentals, Design, Construction and Operation, Springer Heidelberg Dordrecht London New York, 548 p. ISBN: 978-3-642-22937-4.

IEC 61400-1, 2005, Wind Turbines - Part 1: Design Requirements, 3th Edition.

IEC 61400-2, 2006, Wind Turbines - Part 2: Design Requirements for Small wind Turbines, 2st Edition. 
Kline, S. J., and McClintock, F. A., 1953, Describing the Uncertainties in Single Sample Experiments, Mechanical Engineering.

Manwell, J. F., McGowan, J. G., and Rogers, A. L., 2002, Wind Energy Explained: Theory, Design and Application, Wiley.

Verdum, V., 2013, Projeto de um Aerogerador com Segurança Inerente para Aplicação Urbana, Master Thesis, PROMEC, UFRGS. (in Portuguese) 